\title{
An Integrated Simulation and Virtual Cellular Manufacturing System Concept Approach for Maintenance Policy Selection
}

\author{
Jamileh Hayati (iD) and Sohrab Abdollahzadeh \\ Department of Industrial Engineering, Urmia University of Technology, Urmia, Iran \\ Correspondence should be addressed to Sohrab Abdollahzadeh; s.abdollahzadeh@uut.ac.ir
}

Received 30 May 2021; Accepted 2 August 2021; Published 13 August 2021

Academic Editor: Noorbakhsh Amiri Golilarz

Copyright (C) 2021 Jamileh Hayati and Sohrab Abdollahzadeh. This is an open access article distributed under the Creative Commons Attribution License, which permits unrestricted use, distribution, and reproduction in any medium, provided the original work is properly cited.

\begin{abstract}
The main purpose of this study is to present a new hybrid approach to select the appropriate maintenance policy (NET) of machines utilizing analytic network process (ANP), computer simulation, and the concept of virtual cellular manufacturing system (VCMS). Since conventional methods select only one NET policy for all machines or production lines, the performance of machines that do not conform to the selected policy is reduced. In the proposed method, the information of the functional parameters of the machines is extracted by means of computer simulation and there is no need for expert opinion. Next, the appropriate net policy for each machine is selected using the ANP method. To reduce the diversity and complexity of NET applications, machines are grouped using the concept of virtual cellular manufacturing system based on the similarity of NET policies. A NET program is prepared for each group of machines. The proposed approach is used in a production unit with three widely used NET policies, and its efficiency was proved by comparing the results with conventional methods.
\end{abstract}

\section{Introduction}

One of the ways to achieve high productivity in production units is to have the right preventive and maintenance (PM) policy [1]. It is crucial to have a high productivity line to reduce costs [2]. One of the major obstacles to achieving the goals of manufacturing companies is the sudden breakdown of devices that have a direct impact on production [3]. Preventive and maintenance cost varies from 15 to 70 percent of total production cost [4].

PM is a set of activities that are clearly planned and performed to prevent the sudden breakdown of machinery, equipment, and facilities [5]. The main purpose of PM in a system is to extend the life of devices with minimum cost and maximum efficiency during the operation period [6].

However, proper preventive and maintenance policies directly affect the profitability of the organization; the lack of proper PM planning reduces the life of the equipment [7]. Different policies have been stated for the PM; each of them has advantages and disadvantages depending on the type of machine [8]. Taking advantage of the appropriate PM policy reduces the costs of a manufacturing organization [9]. According to [10], in many cases, preventive PM improves the performance of machinery due to more imposing defects, and repairing is only useful to items that have a certain pattern of damage.

Many studies have been done on the evaluation of the efficiency and effectiveness of each PM policy and the selection of the best one $[11,12]$. Selecting the right PM policy does not depend on a single criterion and is considered a multicriteria decision-making issue [13]. The share of research on the use of multicriteria and multiobjective decision-making tools has been high $[14,15]$. There are three main steps in the process of preparation for multicriteria decision-making [16]. First, determining the relevant criteria and options. Then, determining the relative importance of the criteria and performance of the options on the criteria. Finally, rank each option and select the best choice [17]. In multicriteria decision-making methods, criteria such as safety, cost, added value, and feasibility are selected to choose the best policy or a combination of different types of PM policies $[18,19]$. The weight and values of the criteria 
should be derived from the actual performance of the devices and production lines. However, due to the high cost or lack of required time, it is estimated by experts [20]. Due to the low number and high cost of experts, some research has used low-cost methods such as computer simulation to determine the criteria values $[21,22]$.

In a multiproduct manufacturing unit, the performance of the equipment on different production lines is different and requires separate PM policies so that a specific policy may be appropriate only for a set of equipment and may not be effective for another set. While in most conventional methods, a PM policy is chosen for the whole company or production lines [23]. If there is a need for several different policies in a manufacturing company, similar policies should fall into one category. Also, the concept of cellular manufacturing has been used to group different network policies [24].

Most NET policy selection methods use multicriteria decision-making tools that require the selection of appropriate criteria. These methods can be classified into two general categories. In the first method, only one NET policy is selected for the entire production machinery. But in the second method, for each production line, a separate NET policy is selected.

Studies have shown that in conventional methods, a number of machines are not compatible with the NET selection policy for all machines or production lines. Therefore, these methods have limited efficiency due to insufficient attention to the specific characteristics of machines in selecting the appropriate NET policy. As a result, new high-performance methods are essential for selecting the appropriate NET policy.

It should be noted that the new methods will require a lot of functional information from the machines as well as a variety of NET policies. In this regard, the capabilities of computer simulation softwares can be used to reduce the problem of selecting experts and the impact of their personal opinion. Clustering can reduce complexity [25]. It also reduced the diversity and complexity of NET programs by clustering similar machines in terms of NET policies.

In the present study, a new approach has been proposed by using computer simulation, ANP method, and the concept of the virtual cell to select the appropriate PM policy for the machine. The procedure is that the widely used PM policies and their evaluation criteria are extracted and selected from written sources. In the following, the required matrices of the ANP method, including policycriterion and criterion-criterion, preparation, and appropriate PM policy of each machine, are selected. Then machines are grouped based on the similarity of the PM policy. If the number of machines belongs to each policy is large, there is a possibility of creating a variety of PM programs. In order to reduce the variety of PM programs, all machines of that policy are formed in a similar virtual cell. In fact, the machines are not physically moved, but the machines that belong to each cell are subjected to the same PM program. Important research innovations include the following:
(1) Choosing a suitable PM policy for each machine using simulation and without the use of expert opinion.

(2) Grouping machines based on similar PM policies regardless of location.

(3) Applying the concept of virtual cellular manufacturing system (VCMS) in order to result in cell formation of policy machines with a relatively large number of machines. This act reduces the variety of PM programs and performs operations on similar cells without altering the physical location of the machines.

The structure of the current research is as follows and will be described in the new methodology and proposed model in Section 2. In Section 3, the results of the proposed approach to data mining are presented. Finally, the discussion, conclusion, limitation, and future research proposals are represented in Section 4.

\section{Research Methodology}

The main goal of the current study is to provide an approach to selecting the most appropriate PM policy for each machine in a multiproduct manufacturing system. This action uses three tools of managerial, analytical decision-making: ANP, computer simulation, and the concept of VCMS. The conceptual scheme of the proposed approach is shown in Figure 1.

The research steps are explained in the following. Finally, the efficiency of the proposed approach is compared with conventional methods (Types A and B) [26].

2.1. Initial Steps and Basic Information. At this step, the evaluation criteria and the most used PM policies are selected. Also, the main activities of the PM are determined in each PM policy. However, the selection of experts is specific to common methods and does not include the proposed approach, but it is necessary to compare the results of the proposed model with conventional methods.

2.1.1. Selecting PM Criteria. Selection criteria can be defined as the characteristics, skills, and abilities of a policy that can effectively perform a given task. They are used to identify the right strategy [27]. Different categories of PM criteria are provided $[11,28,29]$. The authors of [30] have classified NET criteria into four main groups: cost, value-adding, safety, and availability. Each criterion, in turn, has subcriteria [31]. In the proposed approach, 12 subcriteria from the 4 main groups of criteria that can be calculated by computer simulation are selected as given in Table 1.

2.1.2. Selecting PM Policies. The types of PM policies are condition-based maintenance (CBM), predictive maintenance $(\mathrm{PDM})$, total productive maintenance (TPM), corrective maintenance (CM), and reliability-based maintenance (RBM). Corrective, preventive, and predictive 


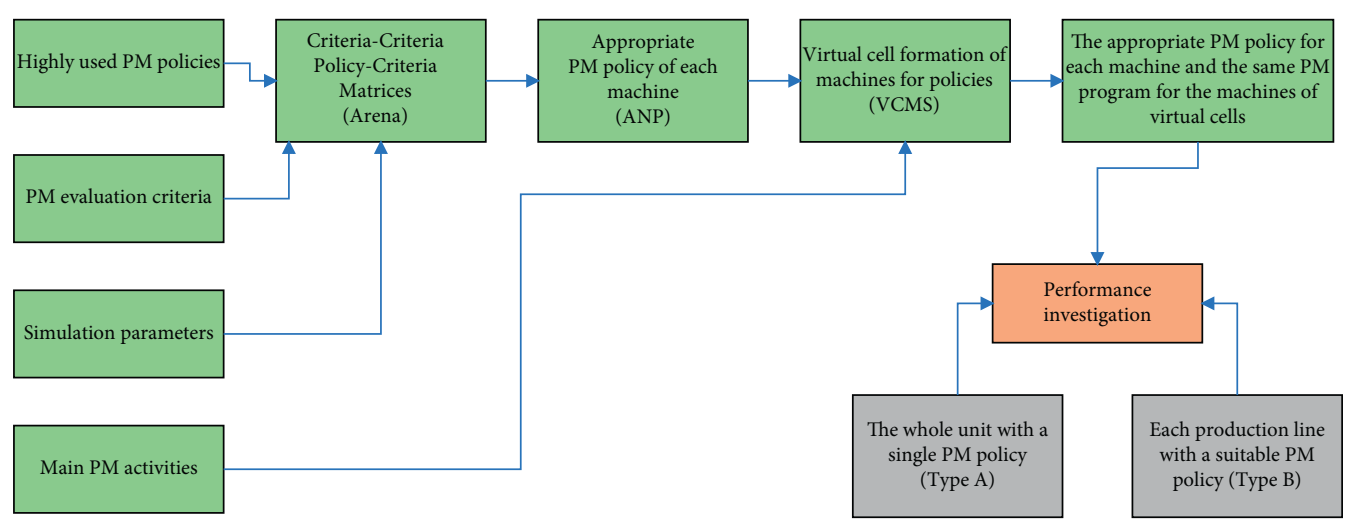

FIGURE 1: The conceptual framework of the hybrid approach.

Table 1: Criteria and subcriteria of selecting PM policies.

\begin{tabular}{|c|c|c|c|c|c|c|c|}
\hline & Cost & & Value adding & & Safety & & Availability \\
\hline$C_{1}:$ & Capital cost & $C_{4}:$ & Reliability & $C_{7}:$ & Operator skills & $C_{10}:$ & Facility utilization \\
\hline$C_{2}$ : & Running cost & $C_{5}:$ & Capability & $C_{8}:$ & Flexibility & $C_{11}:$ & Resource availability \\
\hline$C_{3}:$ & Maintenance downtime & $C_{6}:$ & Repair load & $C_{9}:$ & Efficiency & & \\
\hline
\end{tabular}

$\mathrm{PM}$ policies are the most common policies in an effective PM management [31], which have also been used in current research.

2.1.3. Selecting Experts. This step is specific to conventional methods (Types A and B), and a sufficient number of PM experts are selected to perform pairwise comparisons between criteria and policies.

\subsection{Selection of the Appropriate PM Policies}

2.2.1. ANP. Although both the ANP and the hierarchical analysis process take precedence over pairwise comparisons, there are differences between them [32]. Multiobjective models are used to select appropriate PM policies [33]. A network analysis method has been used to select the appropriate PM policy. This method uses the super-matrix approach. At this step, the pairwise comparison criteria of the policy-criterion and the criterion-criterion must be completed. In conventional methods, these tables are completed by experts. In this method, there is a problem with supplying a large number of experts and also applying the possible manner of experts [34]. Computer simulation tools are used to solve the problem of the effect of experts' judgment on determining the values of criteria, pair comparison, their weight, and also the relationship between criteria in the ANP technique.

2.2.2. Computer Simulation. In the proposed model of the current research, regardless of the physical location and how the machines are installed in the production lines, the appropriate policy for each machine is selected separately. Therefore, considering the number of policies, there is the simulation for each machine, and the values of the policycriteria and the criteria-criteria are calculated.
The authors of [35] have studied the optimization of PM systems based on simulation. By examining about 59 articles published between 2000 and 2013, they found results in using simulation techniques in optimizing PM systems, which is summarized in Table 2.

\section{(1) Computer Simulation Model Assumptions}

(1) The model consists of several continuous production lines, and each line consists of several machines

(2) Each production line is a single product that requires a specific sequence to build

(3) Production operations are continuous and in production line form

(4) The cost and time of the production operation are stochastic

(5) The production capacity of each of the lines and the whole factory in each period is constant, known, and limited

(6) Primary input materials to the system are assumed to be unlimited

(7) Start-up time is not considered for the system

(8) The study period or simulation time is 180 days

(9) Conveyors act as transmitters and have no role in PM programming

Hypotheses 1, 2, 3, and 5 are derived from conventional methods. But hypotheses 5 to 7 are new and relevant to current research. Hypotheses 7 and 9 are intended to simplify the model. The eighth assumption also determines the planning period.

(2) Simulation Model Parameters. In order to determine the policy-criterion as well as the policy-policy entry of the matrix directly, it is necessary to determine the simulation parameters in each of the production lines. These parameters 
TABle 2: Simulation application in optimizing PM systems.

\begin{tabular}{lccc}
\hline PM & PDM & CM & PM \\
\hline PM policy in simulation & Asset & PM resources & Dynamic production \\
Simulation techniques & Discrete event & Discrete event and other techniques & Other techniques \\
Optimization models & Advanced models & Classic models & Manual models \\
Advanced models & Integrated models & SA & GA \\
Optimization & Minimum cost & Maximum availability & Maximum output \\
Single objective or multiobjective & Multiobjective & Single objective & \\
\hline
\end{tabular}

are extracted through machine-building documentation. For example, the parameters of the Nugget production line, as described in Table 3, include failure time, repair time, repair cost, process time, production cost, and waste cost.

Using the Arena version 13.5 software, a computer simulation model is developed. The construction, validation, entry of information, and reporting of models in the current research is in accordance with the method of [36]. In order to test the structural error of the model, the results of simulation with real data are examined to confirm the accuracy of the prediction results of the model. For this purpose, all the studied parameters in the simulation are considered definitively and reviewed and controlled in Excel software. If the results obtained from the simulation are similar to the results of the statistical calculations, the accuracy of the model results is confirmed. At the end of this step, the machines are grouped regardless of their location and only based on the same PM policy.

2.3. Virtual Cell Formation. Cellular production is an industrial application of group technology concepts and is a production philosophy in which similar parts are produced, designed, identified, and grouped in order to take advantage of their similarity. This concept was first proposed by [37].

Sometimes moving machines may not be physically possible or cost-effective. In order to overcome this problem, there are approaches in which one of them is VCMS. Unlike static and classic cellular production, in a virtual cell system, machines, parts, and workers are temporarily grouped for a period of time. The grouped machines are not necessarily the same. If the demand pattern changes from one period to another, the machines in each cell may be transferred virtually to another part [38].

There is a PM program because of the number of machines in each PM policy, and this matter increases the complexity of the proposed model in practice; as a result, PM programs must be reduced by using techniques. To this end, in policies where the number of machines are so many, the machines are formed as cell according to the same PM program and with the help of the concept of virtual cellular production.

In the current research proposal, if the number of machines in each policy is more than 5 , the machines will organize as cell layouts in virtual cells that have a similar PM program. If needed, the number of machines can be changed, and the number of cells can be controlled. With this act, the machines are subjected to a similar program to the PM with no need for physical movement. By changing demand or other production conditions in the next periods, the position of machines in virtual cells may change. In order to cell layout machines in any PM policy, it is necessary to select the PM activities related to that policy. For example, these activities for preventive PM are described in Table 4 [39].

Based on the documents submitted by the manufacturing factory, the requirements of each machine will be determined by the selected PM policy activities. The result will be a matrix, including the numbers 0 and 1 . This matrix for machines that belong to the Preventive PM Policy is shown in Table 4. With the help of the mathematical model, machines are formed as cell layout based on the similarity of activities. This model is described as follows:

Indices:

$i$ : index for activities $(i=1,2, \ldots, P)$

$j$ : index for machines $(j=1,2, \ldots, M)$

$k$ : index for clusters $(k=1,2, \ldots, C)$

Parameters:

rij: 1 if machine $j$ requires activity $i$; 0 , otherwise $e$ : minimum number of machines should be assigned to a formed cluster

A: large positive number

Decision variables:

$X i k: 1$ if activity $i$ is assigned to cluster $k$; 0 , otherwise $Y j k: 1$ if machine $j$ is assigned to cluster $k$; 0 , otherwise $Z k: 1$ if cluster $k$ is to be formed; 0 , otherwise

Objective function:

$$
\begin{aligned}
\operatorname{Min} Z= & \sum_{k=1}^{C}\left(\sum_{i=1}^{P} \sum_{j=1}^{M} X_{i k} Y_{j k}-\sum_{i=1}^{P} \sum_{j=1}^{M} r_{i j} X_{i k} Y_{j k}\right) \\
& +\sum_{k=1}^{C} \sum_{i=1}^{P} \sum_{j=1}^{M} r_{i j} X_{i k}\left(1-Y_{j k}\right) .
\end{aligned}
$$

Constraints:

$$
\begin{aligned}
& \sum_{k=1}^{C} X_{i k}=1, \quad \forall i, \\
& \sum_{i=1}^{M} X_{i k} \leq A \times Z_{k}, \quad \forall k, \\
& \sum_{k=1}^{C} Y_{j k}=1, \quad \forall j,
\end{aligned}
$$


TABLE 3: Nugget production line machines simulation parameters.

\begin{tabular}{|c|c|c|c|c|c|c|c|}
\hline \multirow{2}{*}{ Machine } & \multirow{2}{*}{ Process } & \multicolumn{6}{|c|}{ Production line parameters } \\
\hline & & Failure time & Repair time & Repair cost & Process time & Production costs & Waste costs \\
\hline$M_{11}$ & Material preparation & TRIA $(115,150,200)$ & EXPO (1.5) & 6500 & 50 & 10 & 10 \\
\hline$M_{12}$ & Material injection & TRIA $(90,100,120)$ & EXPO (2.5) & 3000 & 25 & 3 & 3 \\
\hline$M_{13}$ & Spraying powder & TRIA $(40,115,150)$ & EXPO (1.5) & 2000 & 30 & 5 & 5 \\
\hline$M_{14}$ & Cooking and freezing & TRIA $(120,180,240)$ & EXPO (1.5) & 2800 & 50 & 3 & 3 \\
\hline$M_{15}$ & Packaging & TRIA $(25,45,60)$ & EXPO $(0.5)$ & 2000 & 45 & 7 & 7 \\
\hline
\end{tabular}

TABle 4: PM activities for preventive PM policy.

\begin{tabular}{cccc}
\hline$O_{1}:$ & Inspection & $O_{7}:$ & Take reading \\
$O_{2}:$ & Predictive maintenance & $O_{8}:$ & Lubrication \\
$O_{3}:$ & Cleaning & $O_{9}:$ & Schedule replacement \\
$O_{4}:$ & Tightening & $O_{10}:$ & Interview operator \\
$O_{5}:$ & Operating & $O_{11}:$ & Analysis \\
$O_{6}:$ & Adjustment & & \\
\hline
\end{tabular}

$$
\begin{gathered}
\sum_{j=1}^{M} Y_{j k} \leq A \times Z_{k}, \quad \forall k, \\
\sum_{j=1}^{M} Y_{j k} \geq e \times Z_{k}, \quad \forall k, \\
X_{i k}, Y_{j k}, Z_{k} \in\{0,1\}, \quad \forall i, j, k .
\end{gathered}
$$

\section{Linearization:}

The objective function of the model is a nonlinear equation due to the multiplication of the variables $X_{i k}$ and $Y_{j k}$. Let us define the following new variable.

$$
W_{i j k}=X_{i k} Y_{j k} \text {. }
$$

Hence, the following constraints should be added to the original mathematical model [40]:

$$
\begin{aligned}
& W_{i j k}-X_{i k}-Y_{j k}+1.5 \geq 0, \quad \forall i, j, k, \\
& 1.5 \times W_{i j k}-X_{i k}-Y_{j k} \leq 0, \quad \forall i, j, k .
\end{aligned}
$$

Now, we have linear programming as follows:

$$
\begin{aligned}
\operatorname{Min} Z= & \sum_{k=1}^{C}\left(\sum_{i=1}^{P} \sum_{j=1}^{M} W_{i j k}-\sum_{i=1}^{P} \sum_{j=1}^{M} r_{i j} W_{i j k}\right) \\
& +\sum_{k=1}^{C} \sum_{i=1}^{P} \sum_{j=1}^{M} r_{i j}\left(X_{i k}-W_{i j k}\right) .
\end{aligned}
$$

Constraints include equations (2)-(7), (9), and (10).

With the implementation of the linear model with the help of Lingo software, the machines of each policy are assigned to the cells. For example, the result of the cell formation of 9 machines to receive preventive PM policy activities is shown in Figure 2.

2.4. Calculation and Comparison of the Efficiency of the Methods (Types A and B). At this step, the efficiency of the production lines is calculated with the policies and the selected PM program and also compared with the performance results of the two conventional methods (Types A and B).

\section{Case Mining}

The proposed approach in current research has been validated by using case mining. The steps of case mining are exactly in line with the proposed model. In the following, a description of the steps of case mining will be explained.

3.1. Initial Steps and Basic Information. This study was performed on a production unit of Iranian meat and protein products, including three production lines: Nugget, Burger, and Sausage. The number of products is 3, the number of production lines is 3 , and the number of machines is 15 . The other assumptions of the proposed approach are precisely the same. According to previous explanations, PM policies are corrective, preventive, and predictive. The criteria and subcriteria for selecting the appropriate policy for PM include 12 criteria, as described in Table 1 . Since conventional approaches require the opinion of experts for pairwise comparisons, 5 persons were selected, including 3 experts in the field of PM and 2 experts in the field of food industry machines.

3.2. Selecting the Appropriate PM Policies. In the new proposed method, it is necessary to determine the simulation parameters of the production lines. By conducting field studies on production line documentation, the parameters of all three production lines, including failure time, repair time, repair cost, process time, production costs, and waste costs, were extracted. As an example, these parameters for the Nugget line, which has 5 machines, are described in Table 3.

In the proposed model of the current research, computer simulation models are made according to the parameters of the machines. PM computer simulation model has been developed in the study company considering all the parameters of machines and the number of PM policies. For example, the developed model for the study company is related to preventive PM policy, as shown in Figure 3.

In order to check the accuracy of the simulation models and ensure their correct performance, the expected results of the model solution according to the input data were created in Excel software and compared with the output of the models. The results were very close, and, as a conclusion, the validity of the models was confirmed. 


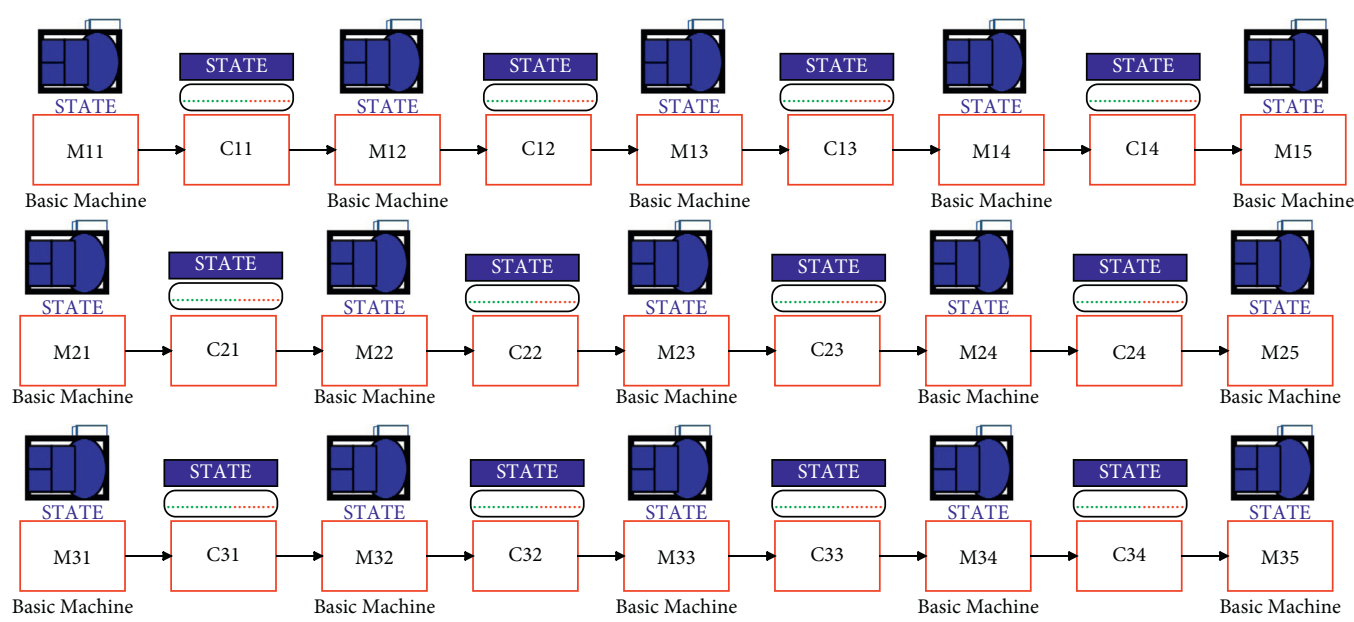

FIgURE 2: Clustering of machines for preventive PM policy.

\begin{tabular}{c|cccccccccccc}
\multicolumn{1}{c}{} & $\mathrm{O}_{4}$ & $\mathrm{O}_{6}$ & $\mathrm{O}_{10}$ & $\mathrm{O}_{5}$ & $\mathrm{O}_{9}$ & $\mathrm{O}_{1}$ & $\mathrm{O}_{2}$ & $\mathrm{O}_{3}$ & $\mathrm{O}_{7}$ & $\mathrm{O}_{8}$ & $\mathrm{O}_{11}$ \\
\hline $\mathrm{M}_{3}$ & 1 & 1 & 1 & 0 & 0 & 1 & 0 & 0 & 0 & 0 & 1 \\
$\mathrm{M}_{4}$ & 1 & 1 & 1 & 0 & 1 & 0 & 0 & 0 & 0 & 0 & 0 \\
$\mathrm{M}_{9}$ & 1 & 1 & 1 & 0 & 0 & 1 & 0 & 0 & 0 & 1 & 0 \\
$\mathrm{M}_{5}$ & 1 & 0 & 1 & 1 & 1 & 0 & 0 & 0 & 0 & 0 & 0 \\
$\mathrm{M}_{7}$ & 0 & 0 & 1 & 1 & 0 & 1 & 0 & 0 & 0 & 0 & 0 \\
$\mathrm{M}_{1}$ & 0 & 0 & 0 & 1 & 0 & 1 & 0 & 1 & 1 & 1 & 1 \\
$\mathrm{M}_{2}$ & 0 & 1 & 0 & 0 & 1 & 1 & 1 & 1 & 1 & 1 & 1 \\
$\mathrm{M}_{6}$ & 0 & 0 & 0 & 0 & 0 & 1 & 1 & 1 & 1 & 1 & 1 \\
$\mathrm{M}_{8}$ & 0 & 0 & 0 & 1 & 0 & 1 & 1 & 1 & 1 & 1 & 0 \\
\hline
\end{tabular}

FIGURE 3: Production line simulation model for preventive PM policy.

In order to select the appropriate PM policies, an ANP approach is used. The ANP method used in this research consists of 5 steps [41].

For this purpose, it is first necessary to complete the criteria-policy matrix. The results of the implementation of simulation models were obtained for each of the three policies. For example, the values obtained for the criteriapolicy matrix for the first machine of the Nugget production line are as described in Table 5.

Arena software has a tool called a process analyzer that allows you to extract the best possible performance for changing variables and sensitivity analysis. The techniques used in this tool are based on theories presented by Hong and Nelson [42]. By using this tool, the relationships between the PM criteria for the first machine of the Nugget production line are calculated and are shown in Table 6.

The criteria-policy matrix is normalized, and the relationships between the matrix of criteria and the weight of the criteria are obtained. For example, the result of the weights for the first machine of the Nugget production line is given in Table 7.

Finally, the preventive PM policy was chosen for the first machine of the Nugget production line. Similarly, calculations were repeated for other machines, and appropriate policies were obtained. These results are shown in Table 8. In order to compare the efficiency of the proposed model in current research with conventional methods (Types A and B), the most appropriate PM policy was obtained based on the opinion of experts for the entire production unit as well as each of the production lines. The most appropriate policy for all production line machines is preventive policy. The most appropriate policy of PM for the Nugget line was preventive and for the next two lines was predictive.

According to the results of the proposed model, the largest number of machines belongs to the policy of preventive PM (9 devices); the next one was the policy of predictive PM (4 devices) and the policy of corrective PM (2 devices). Therefore, in the next step, preventive PM policy machines will be formed as cell layouts.

According to the results of the proposed model, the largest number of machines belongs to the policy of preventive PM (9 devices); the next one was the policy of predictive PM (4 devices) and the policy of corrective PM (2 devices). Therefore, in the next step, preventive PM policy machines will be formed as cell layouts.

3.3. Forming a Virtual Cell. The machine-activity matrix, which determines the activities required for each machine with a preventive PM policy, is shown in Table 9.

The maximum number of cells is 4 , and the minimum number of machines for each cell is 2 if it is formed. The linear clustering model for preventive PM policy has been solved with the help of "Lingo" and "GAMS" software, the results of which are shown in Figure 2. Due to the linearity of models, the obtained results are optimal global values.

This has two significant achievements. First, the diversity of PM programs has been reduced by approximately $65 \%$, and the application of the model in practice is remarkably facilitated. Second, the cell for each operation team was determined. In this example, operations 4, 6, and 10 are deployed in the first cell, operations 5 and 9 in the second cell, and operations $1,2,3,7,8$, and 11 in the third cell. Obviously, 12 operational services are provided outside the cells, which is the best possible situation.

3.4. Calculation and Comparison of the Efficiency of the Methods (Types $A$ and B). This step is only to compare the efficiency of the proposed model of the current research with conventional methods (Types A and B), and in the running 
TABle 5: Results of the Nugget line criteria-policy matrix with simulation.

\begin{tabular}{lccccccccccc}
\hline Policy & $C_{1}$ & $C_{2}$ & $C_{3}$ & $C_{4}$ & $C_{5}$ & $C_{6}$ & $C_{7}$ & $C_{8}$ & $C_{9}$ & $C_{10}$ & $C_{11}$ \\
\hline CM & 152 & 147 & 147 & 155 & 141 & 140 & 127 & 126 & 119 & 114 & 122 \\
PM & 122 & 118 & 116 & 115 & 113 & 111 & 110 & 104 & 100 & 97 & 94 \\
PDM & 160 & 148 & 153 & 145 & 148 & 137 & 132 & 125 & 124 & 120 & 121 \\
\hline
\end{tabular}

TABLE 6: Results of the criteria-criteria relationship with simulation.

\begin{tabular}{cccccccccccc}
\hline & $C_{1}$ & $C_{2}$ & $C_{3}$ & $C_{4}$ & $C_{5}$ & $C_{6}$ & $C_{7}$ & $C_{8}$ & $C_{9}$ & $C_{10}$ & $C_{11}$ \\
\hline$C_{1}$ & 1 & 2 & 4 & 4.5 & 6 & 4 & 8 & 5 & 7 & 4 \\
$C_{2}$ & 0.5 & 1 & 5 & 4 & 6 & 4 & 5 & 5 & 6 & 4 \\
$C_{3}$ & 0.3 & 0.2 & 1 & 2 & 2 & 0.2 & 2 & 0.3 & 0.3 & 0.3 & 0.3 \\
$C_{4}$ & 0.2 & 0.3 & 0.5 & 1 & 5 & 2 & 4 & 2 & 0.3 & 2 & 0.3 \\
$C_{5}$ & 0.2 & 0.2 & 0.5 & 0.2 & 1 & 0.2 & 2 & 0.3 & 2 & 2 & 2 \\
$C_{6}$ & 0.3 & 0.3 & 5 & 0.5 & 5 & 1 & 5 & 0.3 & 0.5 & 0.3 & 0.3 \\
$C_{7}$ & 0.1 & 0.2 & 0.5 & 0.3 & 0.5 & 0.2 & 1 & 0.3 & 2 & 0.5 \\
$C_{8}$ & 0.2 & 0.2 & 3.3 & 0.5 & 3.3 & 3.3 & 3.3 & 1 & 4 & 0.3 \\
$C_{9}$ & 0.1 & 0.2 & 3.3 & 3.3 & 0.5 & 2 & 0.5 & 0.3 & 1 & 0.3 \\
$C_{10}$ & 0.3 & 0.3 & 3.3 & 0.5 & 0.5 & 3.3 & 2 & 3.3 & 0.3 & 4 \\
$C_{11}$ & 0.3 & 0.3 & 3.3 & 3.3 & 0.5 & 3.3 & 2 & 3.3 & 0.3 & 0.3 \\
\hline
\end{tabular}

TABLe 7: Criteria of weight values by simulation for the Nugget line.

\begin{tabular}{lcccccccccccc}
\hline \multirow{2}{*}{ Criterion weight } & $C_{1}$ & $C_{2}$ & $C_{3}$ & $C_{4}$ & $C_{5}$ & $C_{6}$ & $C_{7}$ & $C_{8}$ & $C_{9}$ & $C_{10}$ & $C_{11}$ \\
& 0.071 & 0.085 & 0.063 & 0.067 & 0.080 & 0.041 & 0.069 & 0.031 & 0.063 & 0.066 & 0.182 \\
\hline CM & 92 & 81 & 76 & 78 & 76 & 74 & 73 & 62 & 59 & 54 & 47 \\
PM & 154 & 152 & 150 & 146 & 141 & 134 & 131 & 120 & 112 & 113 \\
PDM & 157 & 145 & 163 & 139 & 147 & 150 & 148 & 146 & 142 & 139 & 134 \\
\hline
\end{tabular}

TABle 8: Appropriate PM policies.

\begin{tabular}{|c|c|c|c|c|c|c|c|c|c|c|c|c|c|c|c|}
\hline \multirow{2}{*}{ Model } & \multicolumn{5}{|c|}{ Nugget } & \multicolumn{5}{|c|}{ Burger } & \multicolumn{5}{|c|}{ Sausage } \\
\hline & $M_{11}$ & $M_{12}$ & $M_{13}$ & $M_{14}$ & $M_{15}$ & $M_{21}$ & $M_{22}$ & $M_{23}$ & $M_{24}$ & $M_{25}$ & $M_{31}$ & $M_{32}$ & $M_{33}$ & $M_{34}$ & $M_{35}$ \\
\hline \multirow{3}{*}{ Proposed model } & \multirow{3}{*}{$\mathrm{PM}$} & \multirow{3}{*}{$\mathrm{PM}$} & \multirow{3}{*}{$\mathrm{PM}$} & & $\mathrm{CM}$ & & & & $\mathrm{CM}$ & & \multirow{3}{*}{$\mathrm{PM}$} & \multirow{3}{*}{ PM } & \multirow{3}{*}{ PM } & \multirow{3}{*}{$\mathrm{PM}$} & \\
\hline & & & & & & PM & PM & & & & & & & & \\
\hline & & & & PDM & & & & PDM & & PDM & & & & & PDM \\
\hline A policy for each line (Type B) & & & $\mathrm{PM}$ & & & & & PDM & & & & & PDN & & \\
\hline A policy for all lines (Type A) & & & & & & & & PM & & & & & & & \\
\hline
\end{tabular}

Table 9: Matrix of machine-activity for preventive PM policy.

\begin{tabular}{|c|c|c|c|c|c|c|c|c|c|c|c|}
\hline & $O_{1}$ & $\mathrm{O}_{2}$ & $\mathrm{O}_{3}$ & $\mathrm{O}_{4}$ & $\mathrm{O}_{5}$ & $\mathrm{O}_{6}$ & $\mathrm{O}_{7}$ & $\mathrm{O}_{8}$ & $\mathrm{O}_{9}$ & $O_{10}$ & $O_{11}$ \\
\hline$M_{1}$ & 1 & 0 & 1 & 0 & 1 & 0 & 1 & 1 & 0 & 0 & 1 \\
\hline$M_{2}$ & 1 & 1 & 1 & 0 & 0 & 1 & 1 & 1 & 1 & 0 & 1 \\
\hline$M_{3}$ & 1 & 0 & 0 & 1 & 1 & 1 & 0 & 0 & 0 & 1 & 1 \\
\hline$M_{4}$ & 0 & 0 & 0 & 1 & 0 & 1 & 0 & 0 & 1 & 1 & 0 \\
\hline$M_{5}$ & 0 & 0 & 0 & 1 & 1 & 0 & 0 & 0 & 1 & 1 & 0 \\
\hline$M_{6}$ & 1 & 1 & 1 & 0 & 0 & 0 & 1 & 1 & 0 & 0 & 1 \\
\hline$M_{7}$ & 1 & 0 & 0 & 0 & 1 & 0 & 0 & 0 & 0 & 1 & 0 \\
\hline$M_{8}$ & 1 & 1 & 1 & 0 & 1 & 0 & 1 & 0 & 0 & 0 & 1 \\
\hline$M_{9}$ & 1 & 0 & 0 & 1 & 0 & 1 & 0 & 1 & 0 & 1 & 0 \\
\hline
\end{tabular}

model, this step is not required. In order to compare them and prove the efficiency of the proposed method, the utilization of the whole system has been used. First, according to the appropriate policy of the PM, by using simulation, the parameters of the NET are calculated. The values of the total utilization of this current research approach and conventional methods (Types A and B) are in accordance with Table 10 . 
TABLE 10: Comparison of the effectiveness of appropriate policies for methods.

\begin{tabular}{|c|c|c|c|c|c|c|c|c|c|}
\hline & \multirow{3}{*}{$\begin{array}{c}\text { Type A } \\
\text { All lines }(\mathrm{PM})\end{array}$} & \multirow{3}{*}{ Nugget (PM) } & \multirow{3}{*}{$\begin{array}{c}\text { Type B } \\
\text { Burger (PDM) }\end{array}$} & \multirow{3}{*}{ Sausage (PDM) } & \multicolumn{5}{|c|}{ Proposed model } \\
\hline & & & & & \multicolumn{3}{|c|}{ Group $1(\mathrm{PM})$} & \multirow{2}{*}{ Group 2 (PDM) } & \multirow{2}{*}{$\begin{array}{c}\text { Group } 3 \\
(\mathrm{CM})\end{array}$} \\
\hline & & & & & Cell 1 & Cell 2 & Cell 3 & & \\
\hline Number of machines & 15 & 5 & 5 & 5 & 3 & 2 & 4 & 4 & 2 \\
\hline System efficiency & 0.6484 & & 0.7023 & & & & & 0.8748 & \\
\hline
\end{tabular}

3.5. Sensitivity Analysis. The policy and schedule selected for each machine can change under the influence of key factors. In the following, various situations are discussed; those key factors affect the choice of policy and NET program of each machine. These sensitivity analyses can be performed in scenario-based research and the results can be compared with the results of the current research.

3.5.1. Change in the NET Policy Selection Criteria. According to Table 1, in the current study, 11 criteria have been used to select the appropriate NET policy. The type and number of these criteria can be changed according to the type of machines of each manufacturing company. However, the policy of choice for each machine may change.

3.5.2. Change in NET Policies. In the current study, three policies CM, PM, and PDM were used. Depending on the needs of manufacturing organizations and the type of machines, the type and number of NET policies can be changed. In this case, the results obtained for machine policy and application may change.

\subsubsection{Change in Production Line Parameters}

(Case 1) Change in the number of parameters: in the current research, according to Table 3, six performance parameters are considered for each machine. As the number of these parameters increases, the accuracy of the model increases, and the policies chosen for the machines may change.

(Case 2) Change in the type of parameters: according to Table 3, in the current study, out of six functional parameters, four are definite parameters, and the other two parameters are random. Changes in the type of these parameters may change the type of policy selected for the machine.

3.5.4. Change in Cell Formation Type. In the current study, the number of cells that indicate the type of NET program is determined by the model. In practice, as the number of machines in each policy increases, the number of cells may be limited by the model. This decision will change the type of car NET program.

\section{Discussion}

In various studies, different methods have been proposed to select the best NET policy. Most of these methods use multicriteria decision-making tools by selecting criteria. These common methods of choosing the optimal NET policy can be categorized into two general categories. In the first method (A), only one NET policy is selected for all production machines. In the second common method (B), a separate policy is selected for each production line. The results of the study on several articles showed that due to the choice of NET policy for a large number of machines and insufficient attention to the specific characteristics of each machine, the common methods have limited efficiency. As a result, new methods of high-performance NET policy selection need to be introduced, focusing on the specific characteristics of each machine. In this regard, the capabilities of simulation software can be used and the impact of personal opinion of experts can be reduced. Also, by clustering machines according to similar NET policies, it reduces the variety and complexity of NET programs.

\section{Conclusion}

The main focus of the present study is on selecting the appropriate NET policy for a group of similar machines in terms of NET policy. For this purpose, first, with the help of computer simulation, the values of the functional parameters of the machines are extracted. This information is for completing the ANP matrices. In the usual way, this information was given by experts and led to applying personal taste in choosing the NET policy. Next, the appropriate policy for each machine is selected using the ANP method. In this approach, the number of NET executable programs increases and makes the operation more complex. In order to reduce the number of NET applications, similar machines are grouped in virtual cells without physical displacement. For each cell, a NET program is prepared and executed. The results of a case study in a food industry show that the optimal NET policies of some machines located on a production line are different from each other. Also, the results obtained from the executive method were compared with two conventional methods. According to the results, the efficiency of the proposed research method is higher than both conventional methods. Given the limitations of the current research, it is suggested that the sensitivity analyses presented in the current research should be performed in a scenario-based research and the results should be compared with the current research. Increase the accuracy of results and analyses by using decision-making methods with multiple criteria in an uncertainty environment such as FANP. 


\section{Data Availability}

The data used to support the findings of this study are available from the corresponding author upon request.

\section{Conflicts of Interest}

The authors declare that they have no conflicts of interest.

\section{References}

[1] X. Zhang, X. Ming, L. Zhiwen, D. Yin, and Z. Chen, "A reference system of smart manufacturing talent education (SMTE) in China," The International Journal of Advanced Manufacturing Technology, vol. 100, no. 9, pp. 2701-2714, 2019.

[2] H. W.-C. Yeung and N. Coe, "Toward a dynamic theory of global production networks," Economic Geography, vol. 91, no. 1, pp. 29-58, 2015.

[3] A. Van Horenbeek and L. Pintelon, "Development of a maintenance performance measurement framework-using the analytic network process (ANP) for maintenance performance indicator selection," Omega, vol. 42, no. 1, pp. 33-46, 2014.

[4] M. Ilangkumaran and S. Kumanan, "Selection of maintenance policy for textile industry using hybrid multi-criteria decision making approach," Journal of Manufacturing Technology Management, vol. 20, no. 7, pp. 1009-1022, 2009.

[5] M. Zandieh, A. R. Khatami, and S. H. A. Rahmati, "Flexible job shop scheduling under condition-based maintenance: improved version of imperialist competitive algorithm," Applied Soft Computing, vol. 58, pp. 449-464, 2017.

[6] S. H. Khajavi, J. Partanen, and J. Holmström, "Additive manufacturing in the spare parts supply chain," Computers in Industry, vol. 65, no. 1, pp. 50-63, 2014.

[7] S. Khan, P. Phillips, I. Jennions, and C. Hockley, "No fault found events in maintenance engineering part 1: current trends, implications and organizational practices," Reliability Engineering \& System Safety, vol. 123, pp. 183-195, 2014.

[8] R. Palmarini, J. A. Erkoyuncu, R. Roy, and H. Torabmostaedi, "A systematic review of augmented reality applications in maintenance," Robotics and Computer-Integrated Manufacturing, vol. 49, pp. 215-228, 2018.

[9] M.-C. Fitouhi and M. Nourelfath, "Integrating noncyclical preventive maintenance scheduling and production planning for multi-state systems," Reliability Engineering \& System Safety, vol. 121, pp. 175-186, 2014.

[10] M. A. Levin and T. T. Kalal, Improving Product Reliability, John Wiley \& Sons, Chichester, UK, 2003.

[11] R. Barlow and L. Hunter, "Optimum preventive maintenance policies," Operations Research, vol. 8, no. 1, pp. 90-100, 1960.

[12] M. M. A. Malakoutian and M. Khaksar, "SBM model based productivity evaluation,” Eng Transactions, vol. 1, no. 1, 2020.

[13] J. Guo, H. Zheng, B. Li, and G.-Z. Fu, "Bayesian hierarchical model-based information fusion for degradation analysis considering non-competing relationship," IEEE Access, vol. 7, pp. 175222-175227, 2019.

[14] M. Shafiee, "Maintenance strategy selection problem: an MCDM overview," Journal of Quality in Maintenance Engineering, vol. 21, no. 4, 2015.

[15] M. Taleghani and A. Taleghani, "Identification and ranking of factors affecting the implementation of knowledge management based on TOPSIS technique," ENG Transactions, vol. 1, pp. 1-10, 2013.
[16] J. Guo, H. Zheng, B. Li, and G.-Z. Fu, "A bayesian approach for degradation analysis with individual differences," IEEE Access, vol. 7, pp. 175033-175040, 2019a.

[17] S.-H. Ding and S. Kamaruddin, "Maintenance policy optimization-literature review and directions," The International Journal of Advanced Manufacturing Technology, vol. 76, no. 5-8, pp. 1263-1283, 2015.

[18] A. S. Eruguz, T. Tan, and G.-J. van Houtum, "A survey of maintenance and service logistics management: classification and research agenda from a maritime sector perspective," Computers \& Operations Research, vol. 85, pp. 184-205, 2017.

[19] E. C. Özcan, S. Ünlüsoy, and T. Eren, "A combined goal programming-AHP approach supported with TOPSIS for maintenance strategy selection in hydroelectric power plants," Renewable and Sustainable Energy Reviews, vol. 78, pp. 1410-1423, 2017.

[20] M. Madhikermi, S. Kubler, J. Robert, A. Buda, and K. Främling, "Data quality assessment of maintenance reporting procedures," Expert Systems with Applications, vol. 63 , pp. 145-164, 2016.

[21] A. Azadeh, M. Sheikhalishahi, and F. Monshi, "Selecting optimum maintenance activity plans by a unique simulationmultivariate approach," International Journal of Computer Integrated Manufacturing, vol. 29, no. 2, pp. 1-15, 2015.

[22] A. Azadeh and S. Abdolhossein Zadeh, "An integrated fuzzy analytic hierarchy process and fuzzy multiple-criteria decision-making simulation approach for maintenance policy selection," Simulation, vol. 92, no. 1, pp. 3-18, 2016.

[23] N. C. Caballé, I. T. Castro, C. J. Pérez, and J. M. LanzaGutiérrez, "A condition-based maintenance of a dependent degradation-threshold-shock model in a system with multiple degradation processes," Reliability Engineering \& System Safety, vol. 134, pp. 98-109, 2015.

[24] N. Aghajani-Delavar, E. Mehdizadeh, R. Tavakkoli-Moghaddam, and $\mathrm{H}$. Haleh, "A multi-objective vibration damping optimization algorithm for solving a cellular manufacturing system with manpower and tool allocation," Scientia Iranica, 2020, In press.

[25] F. J. Golrokh and A. Hasan, "A comparison of machine learning clustering algorithms based on the DEA optimization approach for pharmaceutical companies in developing countries," Eng Transactions, vol. 1, no. 1, 2020.

[26] D. Klein and E. Hannan, "An algorithm for the multiple objective integer linear programming problem," European Journal of Operational Research, vol. 9, no. 4, pp. 378-385, 1982.

[27] F. T. S. Chan and A. Prakash, "Maintenance policy selection in manufacturing firms using the fuzzy MCDM approach," International Journal of Production Research, vol. 50, no. 23, pp. 7044-7056, 2012.

[28] H. Wang, "A survey of maintenance policies of deteriorating systems," European Journal of Operational Research, vol. 139, no. 3, pp. 469-489, 2002.

[29] L. Wang, J. Chu, and J. Wu, "Selection of optimum maintenance strategies based on a fuzzy analytic hierarchy process," International Journal of Production Economics, vol. 107, no. 1, pp. 151-163, 2007.

[30] E. Triantaphyllou, B. Kovalerchuk, L. Mann, and G. M. Knapp, "Determining the most important criteria in maintenance decision making," Journal of Quality in Maintenance Engineering, vol. 3, no. 1, pp. 16-28, 1997.

[31] S. Zaim, A. Turkyilmaz, M. F. Acar, U. M. Al-Turki, and F. Demirel, "Maintenance strategy selection using AHP and ANP algorithms: a case study," Journal of Quality in Maintenance Engineering, vol. 18, no. 1, pp. 16-29, 2012. 
[32] T. L. Saaty, "The modern science of multicriteria decision making and its practical applications: the AHP/ANP approach," Operations Research, vol. 61, no. 5, pp. 1101-1118, 2013.

[33] A. T. de Almeida, C. A. V. Cavalcante, M. H. Alencar, R. J. P. Ferreira, A. T. de Almeida-Filho, and T. V. Garcez, Multicriteria And Multiobjective Models For Risk, Reliability And Maintenance Decision Analysis, Springer International Publishing, Cham, Germany, 2015.

[34] F. Dweiri, S. Kumar, S. A. Khan, and V. Jain, "Designing an integrated AHP based decision support system for supplier selection in automotive industry," Expert Systems with Applications, vol. 62, pp. 273-283, 2016.

[35] A. Alrabghi and A. Tiwari, "State of the art in simulationbased optimisation for maintenance systems," Computers \& Industrial Engineering, vol. 82, pp. 167-182, 2015.

[36] T. Altiok and B. Melamed, Simulation Modeling and Analysis with ARENA, Elsevier, Amsterdam, Netherlands, 2007.

[37] N. C. Suresh and J. Slomp, "Performance comparison of virtual cellular manufacturing with functional and cellular layouts in DRC settings," International Journal of Production Research, vol. 43, no. 5, pp. 945-979, 2005.

[38] M. M. Paydar and M. Saidi-Mehrabad, "A hybrid genetic algorithm for dynamic virtual cellular manufacturing with supplier selection," The International Journal of Advanced Manufacturing Technology, vol. 92, no. 5, pp. 3001-3017, 2017.

[39] A. Hameed, F. Khan, and S. Ahmed, "A risk-based shutdown inspection and maintenance interval estimation considering human error," Process Safety and Environmental Protection, vol. 100, pp. 9-21, 2016.

[40] M. M. Paydar and M. Saidi-Mehrabad, "A hybrid geneticvariable neighborhood search algorithm for the cell formation problem based on grouping efficacy," Computers \& Operations Research, vol. 40, no. 4, pp. 980-990, 2013.

[41] E. B. Tirkolaee, A. Mardani, Z. Dashtian, M. Soltani, and G.-W. Weber, "A novel hybrid method using fuzzy decision making and multi-objective programming for sustainablereliable supplier selection in two-echelon supply chain design," Journal of Cleaner Production, vol. 250, Article ID 119517, 2020.

[42] L. J. Hong and B. L. Nelson, "A brief introduction to optimization via simulation," in Proceedings of the 2009 Winter Simulation Conference (WSC), pp. 75-85, IEEE, Austin, TX, USA, December 2009. 